\title{
Quan Ho cultural space
}

\author{
Dung Ngo Thi Kim* \\ Hanoi Architectural University, Viet Nam
}

\begin{abstract}
Quan Ho singing is a unique cultural practice originated in Bac Ninh, Northern Vietnam. Various aspects of this custom from historical values to cultural impacts have been thoroughly examined. There is, however, no comprehensive study explores Quan Ho under the scope of urban planning and architecture. In recent years, Bac Ninh has been increasingly urbanized, leading to changes in multiple elements of Quan Ho culture, especially cultural space. This paper focuses on such cultural space, presents publicly available data, and collects data along with qualitative, quantitative and comparative analysis to address the effects of urbanization on Quan Ho cultural space. The paper considers characteristics, factors and changing trends of this cultural space, therefore confirms how transformation of Quan Ho cultural space is unavoidable. The paper also addresses planning and architectural requirements to harmonize between preservation and development. Among these requirements, the paper discusses in detail proper programming to optimize green spaces and limit over-urbanization, as well as planning original Quan Ho villages based on two distinctive models: adaptive preservation and development of new facilities on the old foundation. Proper landuse is suggested to build new living space to accommodate the evolving Quan Ho culture in modern society.
\end{abstract}

\section{Introduction}

Quan Ho singing is a unique cultural practice that originated in Kinh Bac, an old province located in the northern part of Vietnam, which is now Bac Ninh and Bac Giang. Over the past decades, Quan Ho culture has changed completely on many aspects, leading to the alteration of Quan Ho cultural living space. This issue has been mentioned by many researchers. Author C. Ha studied the changes of Quan Họ Performers, Quan Ho cultural space, the organization, the mode of operation of the Quan Ho, the Quan Ho's social behavior and the factors affecting the change Quan Ho culture. His research results confirm: Quan Ho culture is a type of integrated culture with specific characteristics, including physical and intangible cultures such as music arts, performance, costumes and behavior, created and practiced by the Vietnamese in Bac Ninh and an area in Bac Giang. It is also the product crystallized from the cultural traditions of the Kinh Bac region many centuries ago, constantly being developed to this day; the change of Quan Ho living space is inevitable [1]. K. Le et al. said that the main elements of Quan Ho culture are Quan Ho folk songs, the custom of

\footnotetext{
* Corresponding author: dungnkhau@gmail.com
} 
making Quan Ho friends, Quan Ho behaviors; Quan Ho festivals and Quan Ho beliefs [2]. Author A.Tran has studied the diverse expressions of the performing space Quan Ho from the past to the present and considered the change of the way of practicing Quan Ho [3]. Authors H. Le, A. Toan conducted a study about the content, form, place, time and space of Quan Ho singing. In addition, spiritual factors, customs and changes in the practice of Quan Ho through the stages are also mentioned [4], [5]. H. Dinh has looked into the custom of way of practicing Quan Ho then and now [6]. C. Tran has explored cultural activities of Quan Ho in the village, with a case study of Quan Ho village Viem Xa [7]. Literature review shows that, Quan Ho culture and the change of it, including the change of Quan Ho cultural space, have been studied by a number of interested authors in different aspects. These studies described, analyzed and evaluated the changes in Quan Ho culture and simultaneously gave directions to solve the problem. However, these studies mainly focus on artistic cultural aspects and intangible culture. Therefore, in my own research, the author wants to consider the changes of Quan Ho cultural space from the perspective of an architect. Specifically, the research will be focused on the change of Quan Ho cultural space in terms of physical space. The objective is to maintain the Quan Ho cultural space in the age of urbanization and cultural integration, contributing to the preservation of the cultural heritage of the Kinh Bac in contemporary society. With two research questions: How has Quan Ho cultural space changed compared to the past? What are the planning and architectural requirements to maintain and develop the cultural space of Quan Ho?

\section{Methods}

In this article, the author uses a combination of studies. The first is to collect secondary data from available data sources such as books, newspapers, magazines and the internet. The second is qualitative research: group interview (Participants of Quan Ho activities), experts interview (researchers, cultural managers of Quan Ho); and field survey, to conduct synthesis, analysis, comparison and description. The third is quantitative research: Using a survey method with a 2- part multiple - choi questionnaire with 16 questions (closed and open) about the general information of the surveyed people and their opinions about Quan Ho culture and Quan Ho cultural space (More than one answers can be acceptable for some questions. Surveyed areas are concentrated in 6 villages in Bac Ninh province. Select sites randomly from 44 original Quan Ho villages (Viem Xa village, Cham Khe village, Y Na village, Yen Man village, Thi Cau village and Xuan Lo village) to survey subjects in 3 groups (Artisan Quan Ho, members of Quan Ho club and people who do not belong to Quan Ho club), each village has 30 votes. Collect the data by making phone calls or meeting face to face. Consequently use some applications of the software SPSS and EVIE V8.0 to process data, analyze, synthesize, report results and discussion.

\section{Results}

\subsection{The Urbanization setting in Bac Ninh}

Having been an agricultural province with a small and backward urban system, after 23 years since the re-establishment of the province (1997), the urban area of Bac Ninh province has undergone major changes. In 2013, the regional construction planning of Bac Ninh province to 2030, vision to 2050 and 2015, the project of urban planning of Bac Ninh to 2030, vision to 2050 was approved with the goals: Bac Ninh will become a first-class city in the years of the twenty-first century, which is a premise for the province to become a municipality before 2030; the urban network develops in the model of a radial urban cluster; unifying urban and 
rural areas is to ensure that people living in suburban areas enjoy and use quality public facilities as close to urban areas [8]. On that basis, urbanization has taken place rapidly and dramatically. The province has 9 cities from grade 1 to grade 5 up to now.

Table 1. Urbanization Rate of Bac Ninh province

[Source: 2015 Statistical Yearbook and Construction plan of the capital region]

\begin{tabular}{|c|c|c|c|c|}
\hline Year & $\mathbf{2 0 0 0}$ & $\mathbf{2 0 1 5}$ & $\mathbf{2 0 2 0}$ & $\mathbf{2 0 3 0}$ \\
\hline Rate of urbanization & $9,5(\%)$ & $28,6(\%)$ & $38(\%)$ & $55-60(\%)$ \\
\hline
\end{tabular}

It is essential to increase the population scale and density as well as changing the industry structure and the rate of non-agricultural labor in order to achieve the urban standards. Accordingly, the economic structure of Bac Ninh province has gradually shifted from agriculture, forestry and fisheries through the current industry and service to the mainstream after 2030 .

\subsection{Changes in Quan Ho culture}

\subsubsection{The subject of Quan Ho}

Subject Quan Ho are the people who create, practice and preserve Quan Ho culture. They are the people of Bac Ninh, especially those who come from the original Quan Ho villages. Together with the development of society, the subject of Quan Ho also have many changes. In terms of educational background, according to the 2019 statistical yearbook, Bac Ninh population over 15 years old are $98.8 \%$ literate, $4.3 \%$ have elementary education, $6.5 \%$ have intermediate education, $6.3 \%$ have college degree and $10.5 \%$ have university degree or higher. Compared to that in the past 5 years, people's educational qualifications has been upgraded continuously. In terms of occupations, the owners of the old Quan Ho were farmers and craftsmen who were born in Quan Ho village and lived mainly on paddy fields, handicraft production, and trading. Up to now, the economic structure has been shifting in line with the direction of industrialization and modernization of the area, which has led to changes in the anatomy of human resources. Occupation is one of the factors which make Quan Ho culture tend to develop and be more modernized.

Table 2. Labor structure by economic sector in Bac Ninh province [Source: Bac Ninh Statistical Yearbook]

\begin{tabular}{|c|c|c|c|}
\hline Year & Agriculture, forestry and fisheries (\%) & Construction industry (\%) & Service (\%) \\
\hline 2016 & 21,38 & 39,03 & 35,59 \\
\hline 2017 & 18,31 & 38,64 & 43,05 \\
\hline 2018 & 16,98 & 38,66 & 44,36 \\
\hline 2019 & 16,0 & 51,7 & 32,03 \\
\hline 2020 & 3,2 & 74,4 & 22,1 \\
\hline
\end{tabular}

Regarding the background knowledge and practice of Quan Ho, Quan Ho used to be passed down spontaneously in the villages. In detail, the former generation teach the following one by word of mouth. Now, people are able to access Quan Ho through many sources such as media channels, communities, Quan Ho artisans or from professional and non-professional training classes (In high schools, middle schools Bac Ninh Culture, Art and Tourism level, Bac Ninh Radio and Television. In 2013, the Quan Ho Bac Ninh Folk Music Group was established to carry out the following tasks such as collecting, researching, preserving and developing Quan Ho folk songs. Therefore, people's knowledge and practice of Quan Ho have been improved significantly. According to the survey results, $94.3 \%$ of interviewees can sing Quan Ho at different levels. 


\subsubsection{Quan Ho's organization and operation}

In the past, Quan Ho was concentrated in several villages (now called original Quan Ho village). The basic units of Quan Ho are the "Bon Quan Ho" (Quan Ho group). Each original Quan Ho village has at least one male "Bon Quan Ho" and one female "Bon Quan Ho"; "Bon Quan Ho" of one village make friends with "Bon Quan Ho" of another one on the principle that Male "Bon Quan Ho" make friends with female "Bon Quan Ho". Each "Bon Quan Ho" usually has 5 to 7 male or female [9]. Currently, besides the original Quan Ho village, there are also Quan Ho practicing villages (which is the village where the Quan Ho Bac Ninh folk singing activities are organized, recognized by the provincial People's Committee). The core unit of Quan Ho practicing village is the Quan Ho club [10]. Through the development process, the organization of Quan Ho in the original Quan Ho villages has changed. "Bon Quan Ho" has no longer existed. Instead, there is the Quan Ho club with different models. Each club has at least 20 people, even up to hundreds of people.

Traditional Quan Ho has two main modes of operation, which are internal activities (seperated activities of "Bon Quan Ho" in the village without the participation of other villages' "Bon Quan Ho" and exchange activities between Quan Ho villages [11]. Today, Quan Ho has more modes of activities such as competition, show and performance on a professional stage. Currently, the mode of internal activities is limited (accounting for 27\%), the main modes are practicing and passing on knowledge. The mode of exchange between villages Quan Ho is dominant (accounting for 31\%). The most prevalent mode is performing weekly and monthly at theaters, cultural centers Quan Ho, events, on local radio and television (accounting for $42 \%$ ).

Table 3. Degree of preference for modes of operation Quan Họ [Source: The author summarised from the rurvey result]

\begin{tabular}{|l|c|c|c|c|c|c|}
\hline \multirow{3}{*}{ Method } & \multicolumn{6}{|c|}{ Age of surveyed person } \\
\cline { 2 - 7 } & \multicolumn{2}{|c|}{ Young $(<35)$} & \multicolumn{2}{c|}{ Middle-aged (35- 60) } & \multicolumn{2}{c|}{ Elderly $(>60)$} \\
\cline { 2 - 7 } & Like (\%) & $\begin{array}{c}\text { dislike } \\
(\%)\end{array}$ & Like (\%) & $\begin{array}{c}\text { dislike } \\
(\%)\end{array}$ & $\begin{array}{c}\text { Like } \\
(\%)\end{array}$ & $\begin{array}{c}\text { dislike } \\
(\%)\end{array}$ \\
\hline Internal operation & 31 & 69 & 27 & 73 & 62 & 38 \\
\hline Exchange activities & 72 & 28 & 79 & 21 & 53 & 47 \\
\hline Performance activities & 63 & 37 & 56 & 44 & 33 & 76 \\
\hline
\end{tabular}

According to the results in table 4, the exchange activities are the most popular in all three age groups. The second is the performing activity. The third is the internal activity. Thus, Quan Ho now tends to spread, expand beyond the scope of the original Quan Ho villages and change from Quan Ho playing to Quan Ho performing.

\subsubsection{Content and form of singing Quan Ho}

Traditional Quan Ho are songs consisting of a core part of poems, folk, accompaniments and sounds of breath. There are 4 main groups of voices: "Le loi", "Song", "Vat" and "Gia ban", corresponding to three stages of a Quan Ho, which is the opening stage, the middle stage and the last stage. There are 8 forms of Quan Ho singing: "Challenge and response" singing (male - female couple); singing at festivals; singing "canh" (singing at Quan Họ hosting house); singing at rituals; "Cau dao" singing; "Ket cha" (Custom of shacking two villages) singing; congratulation singing; singing "Giai han"[12]. Some forms such as "Cau dao" singing," Giai han" singing has no longer existed. Currently, popular forms of singing are: singing at festivals (91.2\%); congratulation singing (65.7\%); "Canh" singing (47.3\%); "Ket cha" singing (35.6\%) and new forms of singing such as Quan Ho singing festival for the elderly, children, Quan Ho singing contest, Quan Ho singing performance on stage (46.7\%). Some 
lyrics of Quan Ho are modified compared to then original version. The Quan Ho performance modes are also more diverse, including solo, duet, top and chorus, animation, karaoke and mashup.

\subsection{Changes in cultural space Quan Ho}

\subsubsection{Geospatial}

In the past, not all the villages in Kinh Bac but only the villages along the banks of Cau River, Duong River, and Ngu Huyen Khe River had the tradition of singing Quan Ho. In the early 20th century, there are 44 villages of Quan Ho, which are originally from Bac Ninh city, Tien Du district, Yen Phong district and Tu Son town. Currently, 369 Quan Ho villages have been developed to practice [13]. Thereby, it can be seen that the geographical space of Quan Ho has expanded to a much larger scale. Quan Ho has spread to most areas of Bac Ninh province and some other national and international localities.

\subsubsection{Quan Ho village space}

From the rural village comprising only residence and field, Quan Ho Villages have become a multi-functional complex of housing, agricultural production, non-agriculture, small industry, handicraft and service up to now. The process of urbanization and industrialization has affected many aspects of social life, including the space of the villages. Ancient traditional villages have a closed, introverted structure in harmony with an autonomous community and a self-sufficient economy. The typical characteristic is the branching structure of a tree which makes up the ranks of traffic, infrastructure and space; traditional architectural form with low construction density, low - rise houses with campuses, gardens, lakes and ponds; traditional landscape (banyan tree, water station, village communal yard, lake, pond, river and small boats.

The current village structure has no longer been suitable; thus, there has been a modification. The village gate has no longer served as a separation and protection; hence, it was demolished to build new and bigger gates. The old road system has no longer been suitable for motor vehicles and the need to transport goods and materials to develop nonagricultural production activities in the village. As a consequence, it has been expanded and concretized. The village public centers have also been expanded and developed to build new cultural institutions such as cultural houses, schools, and sports centers. Due to the increasing population, the village's residential space has also changed significantly. Housing tends to build more floors with a modern architectural form.

The traditional village scene is undergoing many adverse changes for the practice of Quan Ho with the natural area, green area, landscape being narrowed. During 5 years, from 2016 to $2020,11,264$ ha of agricultural land was converted to non-agricultural land and 105 ha of non-agricultural land which was not residential land become to residential land [14]. As for blue space, Bac Ninh has a dense network of rivers and streams, including 3 inter-provincial rivers, 7 intra-provincial rivers and 14,025 ponds and lakes, mostly concentrated in rural area. Tieu Tuong river which is full of cultural elements and related to the origins of Quan Ho folk songs, is now mostly filled up. Only a short part runs around the foot of Tieu Mountain [15]. Ngu Huyen Khe River with a length of $24 \mathrm{~km}$ flowing through 16 original Quan Ho villages in Tu Son town, Yen Phong district, Tien du district and Bac Ninh city is now seriously polluted [16]. Nhu Nguyet river (called Quan Ho river), river water is polluted and the ecosystem is degraded adversely affect the landscape. Pond system is also zoned and 
occupied into a private space. Some ponds were filled to build works, so they lost their cultural role and ecological value.

\subsubsection{Quan Ho singing space at festivals}

Bac Ninh has 547 festivals a year. Quan Ho participates in most festivals, from the solemn part to the exciting part of the festival, from the village center to the alleys, to each family [17]. Ancient festivals take place mainly in the romantic spaces of nature such as hills, mountains, rivers, lakes, under trees and lawns. Now, this environment has changed a lot. Especially the Lim festival, the biggest festival in Bac Ninh province. The festival space takes place on Lim hill, Lim pagoda and 3 surrounding regions: Noi Due, Lien Bao and Lim [18]. Today's Lim Festival attracts thousands of visitors; therefore, the festival space has changed a lot in terms of scale and characteristic to meet practical requirements. The Quan Ho singing space in Lim festival is currently held on a large stage including huts built on the hill and boats and in the villages around Lim hill. The songs tend to be performance rather than exchanges. Therefore, the space is arranged according to the requirements to perform, not to interact as before.

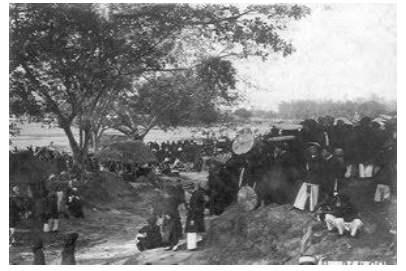

Fig. 1. Hoi Lim in the past [Source: 18]

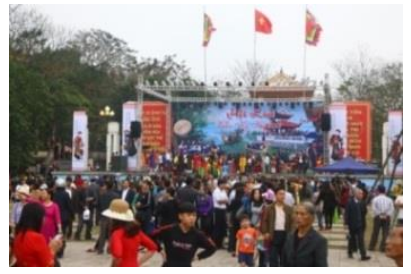

Fig. 2. Quan Ho singing stage at Hoi Lim [Photo: The author]

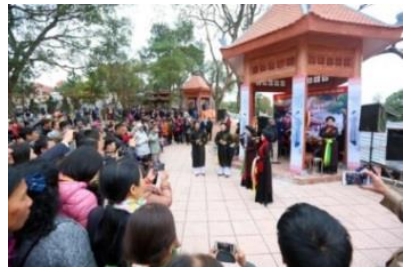

Fig. 3. Quan Ho theater on Lim Hill [Photo: The author]

\subsubsection{Special Quan Ho living space}

Derived from the project called "Lau Quan Ho" created by a person who loves Quan Ho, special Quan Ho living space was built in at Noi Due, Lim to be a gathering place and exchange of "Lien Anh, Lien chi Quan Ho" ( male and female Quan Ho). In other places which do not afford a separate living space for Quan Ho, they take advantage of the empty space in the food stores of the village. After that, some reputable "Lien anh, Lien chi" who had large houses, used their own houses as a place both to live and to do activities in Quan Ho. Those houses are called "Nha chua Quan họ" (Quan Ho hosting house). This is the place where all activities such as sleeping in troupe, voice training, meeting, inviting friends to "Quan Ho" and organizing "Canh" singing take place. This model has developed time by time. Gradually, each "Bon Quan Ho" has its own hosting house. Quan Ho hosting house is compared to the Soul and becomes a special space for Quan Ho [19]. Nowadays, the number of club members is many times as large as the one in the past; thus, Quan Ho hosting house has no longer been active. On the occasion of the festival, only a few artisans hold Quan Ho singing party at private houses on a small scale.

In 2019, Bac Ninh folk songs was registered by UNESCO on the list of the representative intangible cultural heritage of humanity. Implementing measures to preserve the Quan Ho cultural heritage, Bac Ninh has restored 8 Quan Ho hosting house in 8 original Quan Ho villages. Quan Ho hosting houses are built in the campus from 500-3000 m2, including the main house from $100-160 \mathrm{~m} 2$, the secondary house from 50-60 m2, garden, fence and gate. This is an attempt of the local government which aims at maintaining and promoting Quan 
Họ cultural heritage. However, these works have not really satisfied the requirements in terms of the quantity, area and functional spaces serving the current Quan Ho activities.

\subsubsection{Quan Ho singing space in Cultural institution}

In the past, religious and belief institutions were familiar and key living spaces of Quan Ho. Singing rituals, singing "Giai han" take place inside the communal house or the pagoda; singing "Ket cha", singing exchange takes place outdoor at the courtyard and the gate. Today, singing rituals still take place in this space while other forms have moved to new locations. The religious and belief institutions of Quan Ho village still exist; however, the spaces capable of holding Quan Ho singing have been narrowed or having such a small area that does not meet the requirements of the organization of singing Quan Ho. In addition to the traditional living spaces, Quan Ho have added living spaces in newly built cultural institutions in localities throughout the province. Kinh Bac Cultural Center has been put into operation since 2008. This is the largest-scale project of the province, completely and modernly built on a total area of nearly 10 hectares, with functions of culture, arts, meeting. This works includes the following main items such as the audience room for performances and meetings, the conference room, the showroom of cultural - economic - social - scientific and technical achievements and some works outdoors are: performance stage, square, lake ... and auxiliary works [20]. Quan Họ Bac Ninh folk theater was built and put into use in 2019 on an area of 1.9 hectares; 4-storey scale; accommodating nearly 400 spectators [21].

In addition to the two cultural institutions at the provincial level, cultural institutions are also built in the local areas. In particular, at the city and district level, there are 8 works $/ 8$ units (reaching 100\%); at commune, ward and town levels, there are 108 projects / 126 units (reaching 85.7\%); at village and neighborhood levels there are 609 works / 731 units (reaching 83.3\%) [22]. These versatile cultural institutions added more space to the activities of Quan Ho culture. According to the survey results, the daily activities of the village's Quan Ho, such as practice and teaching, take place in cultural houses. Quan Ho living spaces have just appeared recently; nonetheless, they have been effective.

\section{Discussion}

The results presented in section 3 show that the Quan Ho culture has been changing in both quantity and quality. The Quan Ho folk song has changed from singing play and exchange singing to performing for others; from elegant Quan Ho activities to Quan Ho activities with market factors. As a result, the space used for cultural activities Quan Ho must be changed accordingly. On that basis, I will discuss some planning and architectural requirements to ensure that Quan Ho cultural space exists in harmony with the modern community and society.

\subsection{Planning}

According to the planning project, 42/44 of original Quan Ho villages which are located in the core urban area of Bac Ninh province, including Bac Ninh city, Tu Son town, and Tien $\mathrm{Du}$ district, are defined as urban class 1 . Thus, the urbanization process will have a direct impact on the culture, lifestyle, customs of the subjects, objects of Quan Ho, and traditional village space. The issue of preserving and promoting the values of cultural heritages associated with rural lifestyles such as Quan Ho culture will face great challenges. Therefore, planning needs to properly address the relationship between preservation and development. The planned new urban areas should be founded on Quan Ho villages in a way that the newly built ones should not oppose or negate the old facilities, but rather inherit the traditional culture of the old. Quan Ho villages on both sides of the Duong and Cau rivers should be 
planned into green areas to limit urbanization. The maintenance and development of Quan Ho villages can be based on 2 models. The first model is to preserve the original Quan Ho family villages with typical traditional village structure and morphology. Some signature features of this model are bamboo hedges surrounding the village; the traditional village gate - red cotton tree motif; the village road branched in the hierarchy of village roads, alleys, niches; river systems, lakes, dykes; traditional architectural works in harmony with landscapes and natural ecosystems. The second model is to establish a new village structure on top of an old one, accommodating the functional diversity of urbanization and industrialization period and allowing the extroverted spatial structure with wide interconnection capabilities. One distinctive aspect of this model is the traffic system designed as an interconnected network instead of a hierarchically branching road system. This design of traffic system allows good access to motorized traffic. This model also sets up a new form of landscapes and ecology by combining natural ecosystems with artificial landscapes and ecology; creates the imprint, landmark, and identity factors of the design. Model 2 can be applied to other adapted Quan Ho villages.

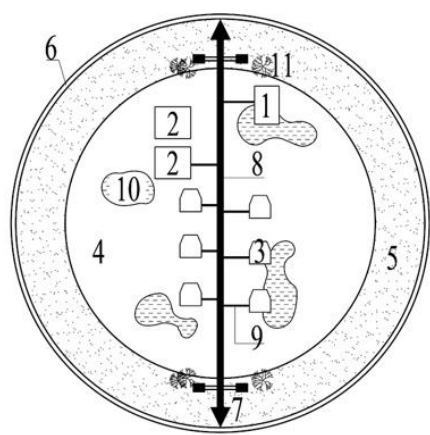

Fig. 4. Model 1. [Sourse: Edit by the author]

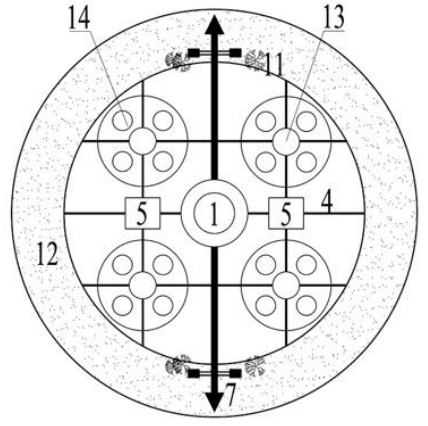

Fig. 5. Model 2. [Sourse: Edit by the author]

1 Places of religious worship; 2 New cultural centers; 3 Ancestral house; 4 Residential areas; 5 Crop fields; 6 Bamboo hedges; 7 Village gate; 8 Main road; 9 Branches; 10 Blue space; 11 Banyan tree, red silk - cotton tree; 12 Green space; 13 Hamlet cultural center; 14 Residential housing.

Venues and boundaries of traditional architectures (communal houses, pagodas, temples, shrines, village gates, village shops, bridges) must be preserved.

Planning must also ensure the land fund to maintain traditional Quan Ho living spaces and create new Quan Ho living spaces. Indeed, the land fund should organize Quan Ho singing centers with a scale of ten thousand people at the provincial level and a scale of thousands people at the district and commune levels. Quan Ho singing centers should be located in places with convenient traffic, closely associated with the history of Quan Ho and traditional festivals (e.g., Quan Ho Bac Ninh complex (associated with "Vua Ba" temple festival), Hong Van mountain area, Lim town, Tien du district, Bac Ninh (in association with Lim Festival). For the commune and district level, it is necessary to set up Quan Ho singing centers for 3-5 adjacent Quan Ho villages or the villages with "Ket cha" together; land fund for investment in the construction of tourist resorts and ecological zones associated with typical historical and cultural relics; land fund for construction of cultural centers for $100 \%$ of villages, communes, districts, cities and similar, including separate Quan Ho living spaces; land fund for construction of "Nha chua Quan Ho " for all original Quan Ho villages, at least one work in each village with a service scale of 50 to 100 people, with full functional spaces such as exchange and communication, teaching, practicing, performing, inviting friends Quan Ho; land fund to maintain and develop several traditional garden houses. 


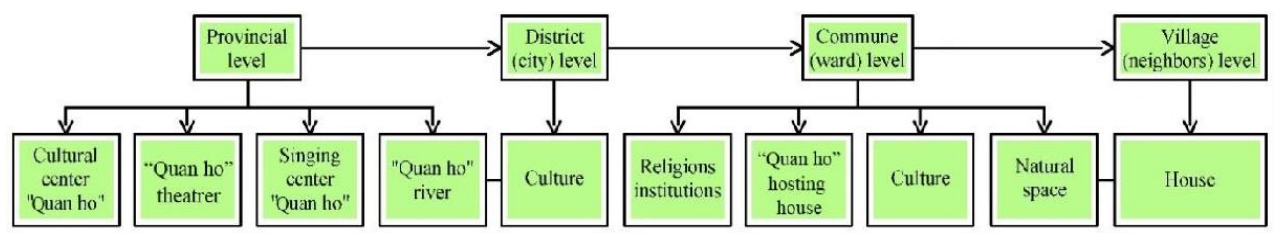

Fig. 6. Diagram describing cultural space Quan Ho. [Sourse: Edit by the author]

\subsection{Architecture and landscape}

It is necessary to conserve the typical landscape of the village such as relic landscape, festive landscape, and natural landscape (hills, mountains, rivers, lakes, dike slopes, trees, lawns). Signature landscape complexes such as Dinh- pagoda-lake; the village gate - the village shop - the village pond; garden- fish pond - house; traditional housing campus; Banyan tree - water station boat also needed to be intact. Rivers associated with Quan Ho living space (Tieu Tuong, Nhu Nguyet, Ngu Huyen Khe) need to be restored with water environment improvement and landscape embellishment on both banks. Traditional Quan Ho quay (Ben Quan Ho) should be reorganized to serve as Quan Ho outdoor performance spaces for visitors and tourists. Water surface spaces that satisfy the requirements of Quan Ho singing on the boat should be selected to embellish, upgrade and complete. Further construction of the marina, performance stage, embankments, seating area can be done to accommodate outdoor performances.

Ancient architectural works and typical folk architecture must be preserved. Each Quan Ho village should maintain and restore at least 2 village gates at the beginning and the end of the main traffic axis of the village. In front of the village gate and on the main roads of the village, open spaces should be organized as a place to culturally exchange and sing Quan Ho. New constructions should have a form that is in harmony with space and traditional architectural form. Traditional houses with courtyards, gardens, low construction density, tiled roofs, and a height not exceeding 3 floors should be maintained to enhance the traditional heritage.

In design of cultural works with the function of organizing Quan ho folk performances, the performance stage deserves the most attention. This space must ensure the interaction between the main performers, supporting performers (e.g., dancers, bands), and the audience. Interactive theatre, Immersive theatre, and Site-specific theatre are suitable options for Quan Ho performances since they encourage the core value of Quan Ho: interaction between audiences and performers. Overall, New Quan Ho is created to inherit and elaborate on traditional original Quan Ho culture, so it must not be far away from its origin.

Theatres in the - round

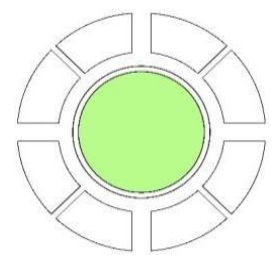

Thrust stage

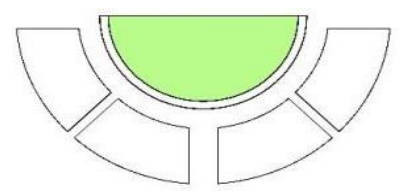

Shape stages

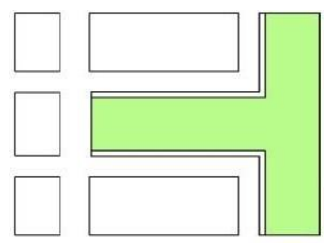

Fig. 7. Some of the theatrical shapes suitable for the Quan Ho performance. [Sourse: The author]

\section{Conclusions}

From the analysis of publicly available and collected data, the study concluded that the current Quan Ho cultural space has changed drastically in both quantity and quality. The changing trend is to expand the scale and the locality; to reduce the natural factor while increasing the artificial 
factor, with purpose and plan. The changing factors are geographical space, village space, festival space, special space for Quan Ho activities. In which, traditional village space has transformed into urban space is the most obvious change factor. Thereby, it can be affirmed that studying the change of Quan Ho cultural space in the material aspect is very important. Based on the changes of Quan Ho cultural space that the research mentioned, the author gave some requirements for planning and architecture as follows: (1) Striking a satisfactory balance between conservation and development; (2) Creating proper subdivisions such that original Quan Ho villages are located in green areas or areas where urban development is restricted; (3) Quan Ho villages need to be comprehensively planned either by being adaptively conserved or developed based on traditional elements; (4) Preserving the location, campus of relics, traditional religious, belief works; (5) Preserving of traditional areas and landscape complexes;

(6) Ensuring land fund to maintain traditional Quan Ho living spaces and create new spaces;

(7) Preserving ancient architecture and typical folk architecture together with developing new architectural works in harmony with traditional architecture.

These are requirements to maintain the traditional Quan Ho cultural space and develop new spaces without hindering the urban development process and the benefits of the community.

\section{References}

1. C. Ha, The transformation of the Quan Ho Bac Ninh culture in the current period, Ph.D. thesis in culture, University of Culture (2018)

2. K. Le, H. Hoac, C. Le, Quan Ho cultural space, Culture and Information Center of Bac Ninh Province, Bac Ninh (2006)

3. A. Tran, Quan Ho performance space - diversity and variation, Quan Ho Bac Ninh Cultural Space - conservation and promotion, Institute of Culture and Information - Bac Ninh Department of Culture and Information, p 48-75 (2006)

4. H. Le, University Magazine, 33 (1963)

5. A. Toan, Phuong Dong magazine, 31-32, 225-247 (1974)

6. H. Dinh, The custom of playing Quan Ho (Kinh Bac origin) now and then, Ph.D. thesis, University of Social Sciences and Humanities, Hanoi (2015)

7. C. Tran, Quan Ho cultural activities, Ph.D. thesis, Ho Chi Minh National Academy of Politics, Hanoi (2016)

8. http: //www.phattriendothi.vn/News/Item/367/29/vi-vn

9. B. Nguyen, Journal of Cultural Heritage 4, 35-37 (2008)

10. http://vbpl.vn/bacninh/Pages/vbpq-print.aspx?ItemID=135376

11. P. Nguyen, P. Luu, N. Tu, V. Nguyen, Quan Ho Bac Ninh folk songs, Culture and Fine Arts Publishing House - Institute of Culture, Hanoi (1962)

12. https: //www.tapchicongsan.org.vn/web/guest/van_hoa_xa_hoi/-/2018/53432

13. Q. Tran, T. Hong, Learn about Quan Ho folk songs, National Culture Publishing House, Hanoi, p15(1997)

14. https://moc.gov.vn/tt/tin-tuc/39660/dieu-chinh-quy-hoach-su-dung-dat-tinh-bac-ninh.aspx

15. H. Nguyen, A. Nguyen, VNU Journal of Social Sciences and Humanities, 4, 3 (2018)

16. file: /// C: /Users/Dell/Documents/thuc-trang-moi-truong-tinh-bac-ninh-5356.html

17. L. Tran, Festivals in Bac Ninh, Bac Ninh Department of Culture and Information (2003)

18. https://sites.google.com/site/ojovietnam/ ngay-hoi-lim

19. https://sites.google.com/site/nguyentocyenman/home

20. N. Nguyen, Managing cultural activities of Kinh Bac Cultural Center, Bac Ninh Province, Master thesis, Central University of Arts and Education (2017)

21. https://bvhttdl.gov.vn/

22. https://vanhien.vn/news 